Z. klin. Chem. u. klin. Biochem.

7. Jg., S. 448-454, September 1969

\title{
Eine Mikromethode zur quantitativen immunochemischen Bestimmung von Proteinen
}

\author{
Von S. Golder, V. Lopez und H. Keller
}

Aus dem Institut für Klinische Eiveißforscbung und der Medizinischen propädeutischen Klinik der Universität Bern (Direktor: Prof. Dr. G. Riva)

(Eingegangen am 16. Mai 1969)

Es wird eine Mikromethode zur quantitativen immunochemischen Bestimmung von Proteinen beschrieben. Sie beruht auf der einfachen radialen Immunodiffusion und stellt eine Modifikation der Mancini-Methode dar. Die Dimensionen der Agarplatten sind dabei wesentlich verkleinert worden. Die Herstellung des Immungels erfolgt durch Uberschichten des erkalteten Agars mit der gewünschten Antiserummenge, wodurch das Mischen einer größeren Menge heißen Agars mit Immunserum vermieden wird. Dies bietet folgende Vorteile:

1. Leichte Ermittlung der optimalen Antigen/Antikörper-Relation und entsprechend Schaffung optimaler Bedingungen für die Bestimmung verschiedener Proteinkonzentrationen. Damit läßt sich die Methode leicht an die verschiedenen Konzentrationsbereiche biologischer Flüssigkeiten (Serum, Liquor cerebrospinalis, Urin usw.) anpassen.

2. Sparsamer. Antiserumverbrauch, indem nur die unmittelbar benötigten Agarscheiben vorbereitet werden.

3. Möglichkeit der Bestimmung von bis zu zwölf verschiedenen Proteinen auf derselben Platte.

\section{A micromethod for the quantitative immunochemical determination of proteins}

A micromethod is described for the quantitative immunochemical determination of proteins. It represents a modification of the MancinI method and it is based on simple radial immunodiffusion. The size of the agar plates has been essentially reduced. The immune gel is prepared by layering the required amount of antiserum on the cooled agar, thus avoiding the mixing of large amounts of hot agar with the immune serum. This offers the following advantages:

1. Easy determination of the optimal antigen/antibody relationship and, therefore, creation of optimal conditions for the measurement of different protein concentrations. The method may thus be easily applied to the different concentration tanges of biological fluids (serum, cerebrospinal fluid, urine, etc.).

2. Economic use of antiserum; only the immediately necessary agar layer is prepared.

3. Up to twelvc different proteins may be determined on the same plate.

Die immunochemische quantitative Bestimmung von Proteinen in Körperflüssigkeiten ist seit der Einführung der Mancini-Technik (1) im Jahr 1965 wesentlich erleichtert worden. Das Verfahren beruht auf dem Prinzip der einfachen radialen Immuno-Diffusion. Es wurde zuerst von Petrie (2) angewendet und später von FeINBERG (3) weiterentwickelt. MANCINI und Mitarbeiter haben die Methode verbessert, eingehend geprüft und deren hohe Empfindlichkeit und große Genauigkeit her-

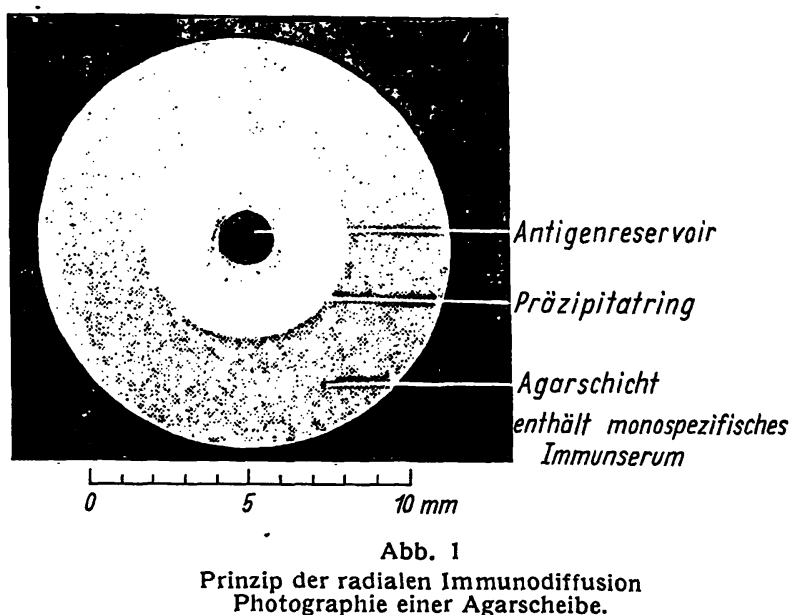

Immunserum: Anotographie einer Agarscheibe.

(1mmunserum: Anti-Albumin, Behring, $20 \mu l$ in $200 \mu l$ Agar. Antigen Bern) vorgehoben. Das Prinzip der Methode ist in Abbildung 1 dargestellt.

Aus einer Agarschicht, welche das monospezifische Antiserum enthält, wird ein Reservoir ausgestanzt, in das die zu untersuchende Antigenlösung (z. B. Serum, Urin, Liquor) eingebracht wird. Die Antigenlösung diffundiert radial in die Agarschicht. In der sogenannten Äquivalenzzone, d. h. im Bereich des für die Präzipitation optimalen Antigen/Antikörper-Verhältnisses, bildet sich ein Präzipitatring, dessen äußerer Durchmesser bei gegebener Antikörperkonzentration von der Antigenmenge abhängt.

Heute sind gebrauchsfertige Immun-Agarplatten im Handel erhältlich (z. B. Partigen Behringwerke, Immunoplates Hyland). Abgesehen vom hohen Preis haben diese Platten vor allem den Nachteil, daß die Konzentration des Antikörpers speziell für die Bestimmung gewisser Plasmaproteine gewählt ist; zur Untersuchung von Flüssigkeiten mit anderem Protein-Gehalt kann der Antikörper=Gehalt nicht angepaßt werden. Darüberhinaus stehen gebrauchsfertige Platten nur für die Untersuchung einer beschränkten Anzahl von Proteinen zur Verfügung. Werden aber derartige Platten vom Untersucher selber hergestellt, ist der Verbrauch an monospezifischem Immunserum relativ groß, die Arbeit heikel und zeitraubend. Wir haben daher eine Modifi- 
kation der Mancini-Methode entwickelt, welche sehr einfach und wirtschaftlich ist und von Fall zu Fall dem Antigen und dem Antikörper angepaßt werden kann.

\section{Vorversuche}

\section{Wabl der Dimension der Agarscbeibe}

Zunächst strebten wir eine Verkleinerung der Dimensionen an. Am rationellsten erschien uns, jede Bestimmung für sich auf einer kleinen Agarscheibe vorzunehmen. Der Verlust an unbenutztem Immungel ist bei einer runden Scheibe am kleinsten, da die Präzipitatbildung radial aus einem Zentrum heraus erfolgt. Für die Messung mit einer einfachen Meßlupe (Meßbereich $10 \mathrm{~mm}$ ) sollen die Präzipitate möglichst nicht über diesen Durchmesser hinauswachsen. $\mathrm{Da}$ wir bei Versuchen mit handelsüblichen Platten zudem festgestellt hatten, daß größere Präzipitate häufig nicht rund, teilweise auch unscharf begrenzt sind, beschränkten wir den Durchmesser der Agarscheibe auf $12 \mathrm{~mm}$. Die Beschränkung der Dimension $c$ rlaubte uns, auf engem Raum eine Anzahl einzelner Bestimmungen durchzuführen. Aus einer $4 \mathrm{~mm}$ dicken Plexiglasplatte ließen wir zylindrische Vertiefungen von $12 \mathrm{~mm}$ Durchmesser ausbohren; auf Grund von Pipettierversuchen erwies sich eine Tiefe von $2 \mathrm{~mm}$ als praktisch. Der flache Boden der so entstandenen Vertiefungen wurde blank poliert (Abb. 2). Auf Grund

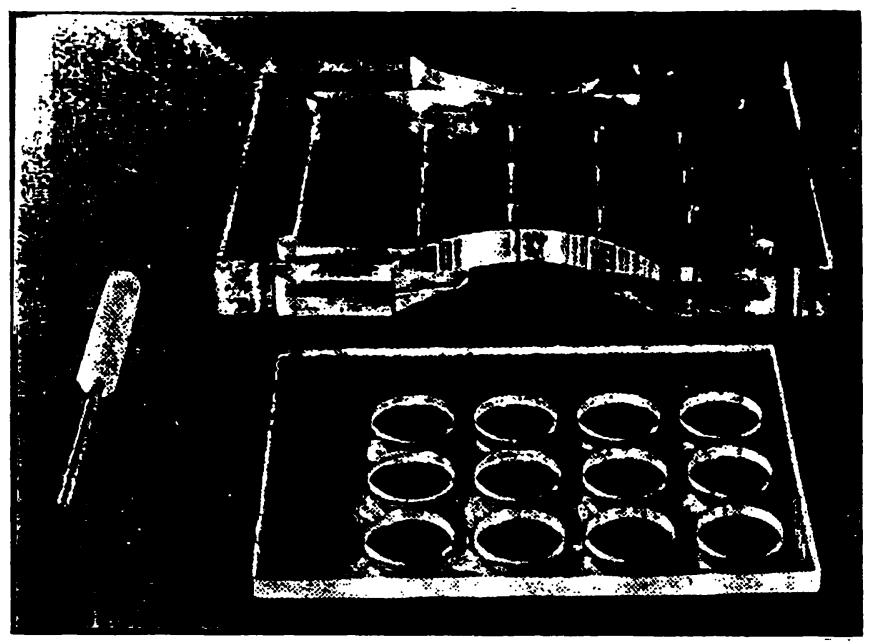

Abb. 2

\section{Instrumentarium}

Unten: Plexiglasplatte, oben: Stanzschablone, links: Stanzkanüle (Photographie). Einzelheiten siehe Text

der unter Vorversuche Punkt 2 beschriebenen Versuche gelang uns der Nachweis, daß die so gewählten Vertiefungen mit einem konstanten Agarvolumen von $200 \mu l$ gefüllt werden können.

Ferner legten wir die äußeren Abmessungen der Plexiglasplatte so fest, daß eine Betrachtung unter jedem Mikroskop möglich ist. Die üblichen Kreuztische erlauben das Festhalțen von $76 \mathrm{~mm}$ langen Objektträgern. In der Breite kann durch Verschieben ein Bereich von rund $60 \mathrm{~mm}$ erfaßt werden. Deshalb entschieden wir uns für eine Platte von $76 \times 60 \mathrm{~mm}$. Bei diesen Dimensionen kann man 12 Bohrungen von $12 \mathrm{~mm}$ Durchmesser anbringen, wobei auf zwei Seiten ein Rand für Beschriftung frei bleibt (Abb. 2). $\mathrm{Da}$ die einzelnen Vertiefungen vollständig getrennt sind, können auf einer Platte bis 12 gänzlich verschiedene Versuche angesetzt werden (z. B. Bestimmung von 12 verschiedenen Plasmaproteinen).

\section{Herstellung der Agarscheiben}

Bei niedriger Agar-Konzentration (um 1\%) und einer Temperatur von etwa $60^{\circ}$ konnte der Agar leicht mit einer gewöhnlichen Glaspipette gegossen werden. Allerdings erwies sich dieses Gel für das Stanzen der Antigenreservoire als zu wenig widerstandsfähig. Bei höherer Konzentration blieb andererșeits ein Teil des Agars in der
Glaspipette zurück, im Reservoir erstarrte das Gel mit gewölbter Oberfläche. Das Erstarren des Agars in der Pipette kann durch Pipettieren mit einer Uberdruckpipette vermieden werden. Dazu eignet sich die Marburg Mikropipette (Eppendorf) sehr gut. Allerdings mußten wir die Handhabung etwas abändern, um die Bildung von Luftblasen zu vermeiden (s. Untersuchungstechnik Punkt 1). Um die Meniskusbildung zu verhindern, müssen die Platten ebenfalls auf etwa $60^{\circ}$ erwärmt werden. Wir legen sie zu diesem Zweck waagerecht auf eine vorgewärmte Glasplatte. Unter diesen Versuchsbedingungen lassen sich befriedigende Schciben mit Agarkonzentrationen bis zu 4\% herstellen.

Somit können wir für unsere Versuche den Agar gebrauchen, den wir auch für die Immunoelektrophorese verwenden. Ein derartiger Agar ist klar und durchsichtig und doch genügend fest (Agar 2,5\% in Veronalpuffer $\mathrm{pH} 8,2$ ).

\section{Herstellung des Immungels}

Nach der Beschreibung von MancinI (1) wird das Immungel durch Mischen des warmen Agars mit dem Immunserum angefertigt. Bei Anwendung dieses Verfahrens stießen wir auf einige nicht unerhebliche Schwierigkeiten. Bereits der Mischvorgang an sich ist heikel. Dabei bilden sich Blasen und Schlieren. Einige Immunseren trüben sich. Darüberhinaus entstehen beim Pipettieren Verluste an Immunserum.

Aus den bisherigen ausgedehnten Erfahrungen mit der Immunoelektrophorese und andern immunochemischen Reaktionen (4, $5,6,7)$ geht hervor, daß die Diffusion von Immunserum im Agar konstanten Gesetzen folgt. Deshalb versuchten wir, die oben erwähnten Schwierigkeiten zu umgehen, indem wir das Immunserum in den erstarrten Agar hineindiffundieren ließen. Mengen bis zu $40 \mu l$ Immunserum werden ohne weiteres innerhalb von $48 \mathrm{Stdn}$. vollständig von einer Agarscheibe aufgenommen. Wie die späteren Versuche zeigten, ist die Verteilung des Immunserums im Agar homogen. In der Regel benötigt man pro Agarscheibe zwischen 5 und $30 \mu l$ eines monospezifischen Immunserums. Zum Pipettieren verwenden wir eine Hamilton Mikroliter Syringe, die ein rasches und genaues Arbeiten ermöglicht. Um ein Austrocknen des Agars zu verhindern, legen wir die Platten während der Antikörperdiffusion in eine Feuchtekammer.

\section{Stanzen der Antigen-Reservoire}

Wir erprobten verschiedene Durchmesser der Antigenreservoire und entschieden uns zuletzt für einen Durchmesser von $2 \mathrm{~mm}$ Kleinere Durchmesser erschweren das Auffüllen des Reservoirs, bei größerem Fassungsvermögen benötigt man mehr Immunserum.

Um beim Stanzen das Zentrum der Agarscheiben zu treffen, und dabei die Seitenwände der Reservoire nicht zu beschädigen, ließen wir eine einfache Stanzschablone herstellen, durch die die Kanüle satt geführt wird (Abb. 2).

\section{Pipettieren der Antigen-Lösung}

Die oben beschriebenen Antigenreservoire fassen etwas mehr als $5 \mu \mathrm{l}$ Flüssigkeit. Um jedoch ein Úberlaufen mit Sicherheit zu vermeiden, füllen wir nur $4 \mu l$ Flüssigkeit ein. Auch dazu eignet sich die Hamilton Mikroliter Syringe vorzüglich, allerdings muß dafür Sorge getragen werden, daß der Rand des Antigenreservoirs nicht beschädigt wird.

\section{Diffusion des Antigens}

Bereits nach weniger als einer Stunde ist der Anfang der Präzipitatbildung als kleiner weißlicher Ring um das Antigenreservoir erkennbar. Der Ring dehnt sich während 12 bis maximal 36 Stdn. aus und erreicht in dieser Zeit seinen definitiven Durchmesser. Dieser Vorgang ist in Abbildung 3 graphisch dargestellt. Wir ließen zwei verschiedene Albumin-Lösungen in Agar mit gleichem Anti-Albumin-Gehalt diffundieren und verfolgten die Präzipitatbildung während $50 \mathrm{Stdn}$. Wie aus der Abbildung hervorgeht, wurde der maximale Ringdurchmesser bei kleiner Konzentration nach 12, bei höherer Konzentration nach 24 Stdn. erreicht.

In anderen Fällen kann die Reaktion auch etwas länger daucrn, aber nach spätẹtens $36 \mathrm{Stdn}$. kann die Messung erfolgen. 


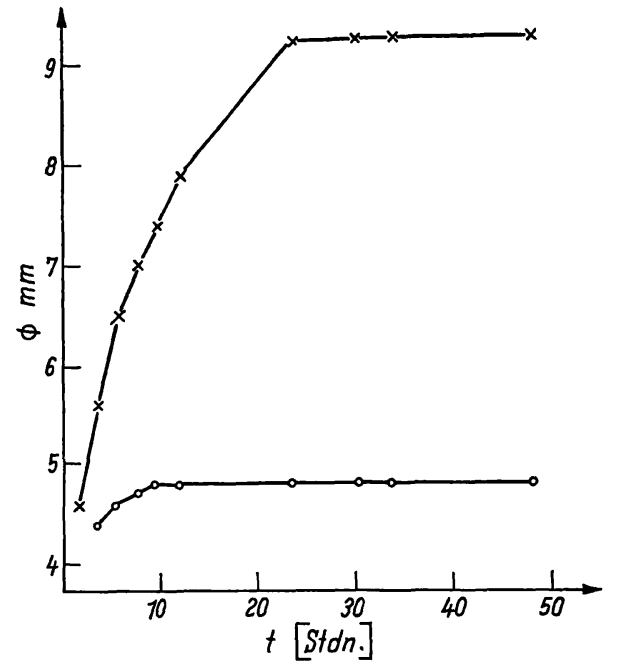

Abb. 3

Abhängigkeit des Präzipitatdurchmessers von der Diffusionszeit Antiserum: Anti-Albumin, SEVAC, $20 \mu l$ pro Agarscheibe Serum: Standard-Human-Serum, Behring, verdünnt auf $1,88 \mathrm{mg} / \mathrm{ml}$ $(X)$ bzw. $0,23 \mathrm{mg} / \mathrm{ml}(0)$ Albumin.

Ablesung des. Präzipitatdurchmessers alle 2 Stdn. während $12 \mathrm{Stdn}$. anschließend nach 24,30,32 und $48 \mathrm{Stdn}$. Der maximale Präzipitatdurchmesser wird bei der höheren Albuminkonzentration nach 24 Stdn. bei der niedrigeren Albuminkonzentration bereits nach $12 \mathrm{Stdn}$. erreicht

\section{Temperatureinflüsse}

Die beschriebenen Versuche wurden bei Raumtemperatur durchgeführt. Durch Inkubation der Platten bei $37^{\circ}$ wird der Vorgang beschleunigt, das Endresultat jedoch nicht beeinflußt. Legt man die Platten während der Präzipitatbildung in den Kühlschrank $\left(4^{\circ}\right)$, wird der Ablauf der Reaktion deutlich verlangsamt, wobei man auch hier die gleichen Endresultate erhält. Nach unseren Untersuchungen werden weder Durchmesser noch Schärfe und Ablesbarkeit des Präzipitatringes von der Temperatur beeinflußt. Schon Mancins und Mitarbeiter (1) haben diese Frage eingehend geprüft und dieselben Resultate erhalten.

\section{Einfluß des $p H$}

Ublicherweise werden Immunreaktionen in leicht alkalischem gepuffertem Agar durchgeführt. Wir haben den Einfluß des pH mit dem gleichen Antigen-Antikörper-System bei pH 5,0, 7,0, 8,2 und 8,6 geprüft. Wir konnten dabei keine ins Gewicht fallenden Unterschiede in der Größe, Dichte und Schärfe des Präzipitatringes feststellen. Für unsere Versuche wählten wir Agar 2,5\% in Veronalpuffer $\mathrm{pH} 8,2$, dem wir eine Spur Merthiolat ${ }^{2}$ ) beigaben.

\section{Die Messung}

Die Präzipitate können in der Regel ungefärbt vor dunklem Grund mit einer Lupe gemessen werden. Flaue Präzipitate werden in seitlichem Licht deutlicher sichtbar. Gelegentlich färbten wir die Präzipitate mit Amidoschwarz bzw. Azocarmin (ganz kurzes Eintauchen in die Farblösung und sofortiges Entfärben). Gemessen wird der äußerste Durchmesser des Präzipitatringes, und zwar in zwei zueinander senkrecht stehenden Durchmessern. Beträgt der Unterschied zwischen zwei Messungen mehr als $2 / 10 \mathrm{~mm}$, muß das Versuchsergebnis als nicht einwandfrei betrachtet werden, und der Versuch sollte wiederholt werden. Als Ursache kommen in detartigen Fällen z. B. in Frage: das Überlaufen des Antigenreservoirs, ein Riß im Rand des Antigenreservoirs.

\section{Instrumentarium und Reagenzien}

\section{Instrumentarium}

Plexiglasplatte (Abb. 2) von $76 \times 60 \times 4 \mathrm{~mm}$ mit 12 zylindrischen Vertiefungen von je $12 \mathrm{~mm}$ Durchmesser und $2 \mathrm{~mm}$ Tiefe als Agarreservoire, wobei oben und links ein Rand für $\mathrm{Bc}$ zeichnungen bleibt. Die Vertiefungen sind poliert, die übrige

1) Merthiolat $=\mathrm{Na}-$ Åthylmercurithiosalicylat
Oberfläche der Platte bleibt rauh, damit die Schrift besser haftet. (Die äußeren Abmessungen wurden so gewählt, daß die Platte auf den Kreuztisch jedes Mikroskops paßt.)

Stanzschablone aus Plexiglas (Abb. 2), die sich deckelartig übè die oben beschriebene Platte 'llemmen läßt. Sie weist 12 durchgehende Bohrungen von $2 \mathrm{~mm}$ Dicke über den Zentren der Agarreservoire auf, die der Stanzkanüle (siche unten) als Führung dienen $^{2}$ ).

Stanzkanüle (Abb. 2) aus rostfreiem Stahl, $2 \mathrm{~mm}$ Durchmesser, innen geschliffen, evtl. mit Griff (aus Holz, Gummi oder ähnlichem) zum Stanzen der Antigenreservoire.

Kanüle aus rostfreiem Stahl, 1 mim Durchmesser, die über einen Schlauch an eine Wasserstrahlpumpe angeschlossen wird. Sie dient zum Absaugen der gestanzten Agarzylinder, wobei durch den geringeren Durchmesser dieser Kanüle die Beschädigung des Randes des Aritigenteservoirs vermieden wird.

Mikropipetten a) Modell Marburg $200 \mu l$ (Eppendorf) zum Pipettieren des Agars

b) Hamilton Mikroliter Syringe 702 NWG $25 \mu l$ mit Arretiervorrichtung zum Abmessen des Antiserums.

c) Hamilton Mikroliter Syringe $10 \mu l$ zum Abmessen der Antigenlösung.

Meßinstrument. Wir verwenden eine Binokularlupe mit eingebautem Meßokular (Olympus, Japan). Eine exakte Messung ist aber auch mit einer einfachen Meßlupe oder mit einem Mikroskop mit Kreuztisch und Meßokular möglich.

\section{Reagenzien}

Agar. Special Agar Noble (Difco) 2,5\% mit Veronalpuffer auf $\mathrm{pH} 8,2$ einge stellt, mit etwas Merthiolat ${ }^{1}$ ) versetzt.

Monospezifische Antiseren. Wir verwendeten folgende AntiHuman-Immunseren vom Kaninchen:

Anti-Albumin

$\left.\begin{array}{l}\text { Anti- saures } \alpha_{1} \text {-Glykoprotein } \\ \text { Anti- } \alpha_{1} \text {-Antitrypsin }\end{array}\right\}$ Behringwerke, Marburg

Anti-Haemopexin

Anti-Coeruloplasmin

Anti-Haptoglobin

Anti- $\alpha_{2}$-Makroglobulin

Anti-Transferrin

Anti-IgG

Anti-IgG

Anti-IgA

Anti-IgM

Referenzlösungen a) Lösung der Reinsubstanz:

Albumin und saures $\alpha_{1}$-Glykoprotein (Behringwerke)

b) Stabilisiertes Standard Human Serum (Behringwerke)

c) Normale Seren (Einzelspender und Pool aus 200 Einzelspendern) aus dem Blutspendedienst des Schweiz. Roten Kreuzes in Bern.

Farblösungen und Entfärber a) Azocarmin-Lösung:

Azocarmin G (Geigy oder Fluka)

Methylalkohol

Eisessig

mischen und filtrieren, anschließend zufügen von

Glycerin

b) Amidoschwarz

Amidoschwarz 10 B (,Bayer") Merck, Darmstadt

Essigsäure 12\%

Na-Acetat $1,35 \%$

mischen und filtrieren, anschließend zufügen von

Glycerin

$4 \mathrm{~g}$

$900 \mathrm{ml}$

$100 \mathrm{ml}$

c) Entfärber

Essigsäure 2\%

Glycerin

$100 \mathrm{ml}$

2) Hersteller unserer Platten und Schablonen: Herr Meier, Mechaniker, Physiologisches Institut der Universität Bern. 


\section{Untersuchungstechnik}

\section{Vorbereitung der Platte}

Die Plexiglasplatten werden gereinigt und mit einem anti-elektrostatischen Tuch (wie cine Schallplatte) abgerieben, waagerecht auf eine warme Unterlage gelegt und bis auf rund $60^{\circ}$ vorgewärmt. Der vorbereitete Agar wird im Wasserbad auf $55^{\circ}$ abgekühlt. Durch mehrmaliges Spülen wird die 200- $\mu$ l-Marburg-Pipette erwärmt, damit Abmeßfehler vermieden werden. Da der Agar nicht sofort erstarrt, verteilt er sich in gleichmäßiger Schicht mit planer Oberfläche im ganzen Reservoir. Um zu vermeiden, daß eine Luftblase auf die Agaroberfäche pipettiert wird, empfehlen wir folgendes Vorgehen: Bei der crsten Füllung sauge man etwas mehr als $200 \mu l$ an, indem man den Kolben etwas weiter als bis zum ersten, jedoch nicht bis zum zweiten Anschlag niederdrückt. Zur Entleerung drücke man nur bis zum ersten. Anschlag. Dabei bleibt ein kleiner Flüssigkeitsrest in der Plastikspitze zurück, welcher den Luftaustritt verunmöglicht. Mit einiger Ubung läßt sich eine konstante Agarmenge einfüllen. Nach Erstarren des Gels ist die Platte bereit. Sie wird bis zum Gebrauch waagerecht in einer Feuchtekammer aufbewahrt.

\section{Die Diffusion des Antikörpers}

Mit der Hamilton Mikroliter Syringe $25 \mu l$ wird die benötigte Menge monospezifischen Immunserums - meist zwischen 10 und $25 \mu l$ - ohne Beschädigung des Agars auf dessen Oberfläche getropft. Das Immunserum verteilt sich sofort gleichmäßig auf der Agarschicht. Während $48 \mathrm{Stdn}$. wird die Platte in der Feuchtekammer bei Raumtemperatur gelagert. Nach dieser Zeit hat sich das Immunserum gleichmäßig im Agar verteilt. Die Platte wird kurz in dest. Wasser, dem etwas Merthiolat beigegeben wurde, geschwenkt, um die nicht inkorporierbaren Reste des Immunserums von der Oberfläche wegzuspülen. Das anhaftende Wasser wird abgeschüttelt, wenn nötig vorsichtig abgesogen. In diesem Zustand können die Platten im Kühlschrank einige Tage aufbewahrt werden, vorausgesetzt, da $B$ sie sich in wasserdampfgesättigter Atmosphäre befinden.

\section{Die Antigendiffusion}

Die Stanzschablone wird deckelartig auf die Platte geklemmt, derart, daß die Bohrungen über die Mitte der Agarscheiben zu liegen kommen. Mit der $2 \mathrm{~mm}$ dicken Kanüle werden jetzt, geführt durch die Bohrlöcher der Schablone, die Antigenreservoire gestanzt. Die Schablone wird entfernt, und mit der dünneren Kanüle werden vorsichtig die gestanzten Zylinder abgesogen (dabei ist besonders darauf zu achten, daß die Wände der Antigenreservoire nicht beschädigt werden, da kleinste Unregelmäßigkeiten ungenaue Resultate zur Folge haben). In die Antigenreservoire füllen wir $4 \mu l$ der zu untersuchenden Flüssigkeit ein. Dazu benützen wir die Mikrosprịtze $10 \mu l$. Auf genaues Abpipettieren muß hier besonders geachtet werden. Die Platte soll für alle Verrichtungen nur während kurzer Zeit außerhalb der Feuchtekammer bleiben, um den Fehler durch Verdunsten gering zu halten.

Die Platte wird nun für $36 \mathrm{Stdn}$. waagerecht in die Feuchtekammer gelegt (in dieser Zeit bilden sich die Präzipitate). Daraufhin werden die Platten zum Auswaschen des ungebundenen Antikörpers für einige Stunden in physiologische $\mathrm{NaCl}-\mathrm{Lösung}$ gelegt (die Präzipitate werden dadurch besser sichtbar).

\section{Die Messung}

Die Platte wird vor dunklem Hintergrund seitlich beleuchtet. Die Präzipitate treten so wie im Dunkelfeld deutlich hervor, und ihr Durchmesser wird mit der Lupe auf $1 / 10 \mathrm{~mm}$ genau gemessen. Damit man vergleichbare Resultate erhält, $m u ß$ die Lupe immer auf denselben Punkt (z. B. auf den obcren Rand des Antigenreservoirs) eingestellt werden. Man mißt zwei senkrecht aufeinanderstehende Durchmesser. Selten beträgt der Unterschied zwischen beiden Durchmessern mehr als $2 / 10 \mathrm{~mm}$. In diesen Fall ist die Bestimmung zu wiederholen (s. oben, Vorversuche Punkt 9)
Die Resultate werden mit Hilfe der im Abschnitt Untersuchungstechnik, Punkt 6 beschriebenen Eichkurve abgelesen.

In der Regel kann man auf eine Färbung verzichten. Bei sehr unscharfer Präzipitatbildung kann die Platte nach Auswaschen (vgl. Untersuchungstechnik, Punkt 3) leicht gefärbt werden, indcm sie für 1-3 Sek. in Amidoschwarz oder Azocarmin getaucht und sofort in $2 \%$ Essigsäure entfärbt wird.

\section{Ermittlung des optimalen Antigen-Antikörperverbältnisses}

Durchmesser und Schärfe der Präzipitate hängen sowohl von der Art und Menge des zu untersuchenden Proteins als auch vom Antikörpergehalt des Agars ab. Deshalb muß für jedes einzelne zu bestimmende Protein und für jeden Konzentrationsbereich desselben sowie für jedes Antiserum das optimale Verhältnis ermittelt werden. Es geht mit anderen Worten darum, die Bildung deutlicher Präzipitatringe bei möglichst geringem AntiserumVerbrauch $z u$ erzielen und dabei einen weiten Konzentrationsbereich des zu bestimmenden Proteins zu erfassen.

Das praktische Vorgehen bei der Ermittlung des optimalen Antigen-Antikörperverhältnisses läßt sich am einfachsten an Hand eines Beispiels darstellen (s. Abb. 4). Mit Hilfe eines be-

\section{soures $\alpha_{1}$-Glykoprotein}

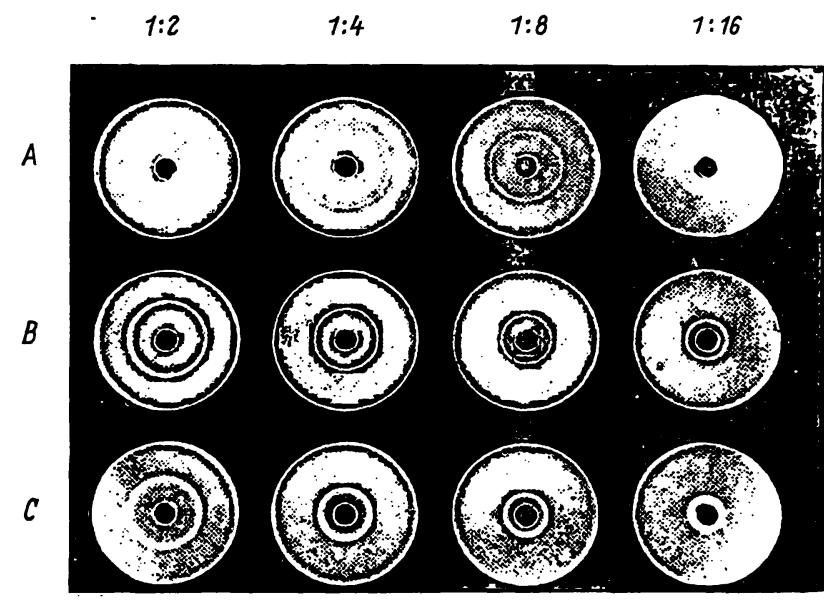

Abb. 4

Ermittlung des optimalen Antigen-Antikörperverhältnisses Antiserum: Anti-saures $\alpha_{1}$-Glykoprotein, Behring

Serum: Normalserum, Pool aus 200 Blutspender-Seren, SRK, Bern Die vier Agarscheiben der Reihen A bis C enthalten je 10 (A), 25 (B), 50 (C) $\mu l$ Antiserum. Vom untersuchten Normalserum wurden Verdünnungen von $1: 2$ bis $1: 16$ hergestellt. Je $4 \mu l$ dieser Serumverdünnungen wurden in die Antigenreservoire jeder Reihe eingefüllt Die Präzipitate der Reihe A sind relativ groß und flau, diejenigen der $^{2}$ Reihe $C$ sehr deutlich, aber zu klein. Deutlich und gut meßbar sind
die Präzipitate in Reihe B.

stimmten Antiserums (in diesem Falle Anti- saures $\alpha_{1}$-Glykoprotein Behring) soll der Gehalt an saurem $\alpha_{1}$-Glykoprotein im menschlichen Serum ermittelt werden. Die Reihen A, B und C der Platte werden mit je 10 bzw. 25 bzw. $50 \mu l$ Antiserum pro Agarscheibe beschickt. Mit jeder Antiserum-Konzentration werden 4 verschiedene Versuche angestellt, nämlich mit 4 verschiedenen Verdünnungen $(1: 2,1: 4,1: 8,1: 16)$ eines normalen menschlichen Serums (Pool aus 200 Blutspendern). Aus der Abbildung geht hervor, $\mathrm{da} B$ in Reihe A (10 $\mu l$ Antiserum) die Ringe flau und bei den höheren Antigen-Konzentrationen (Serumverdünnung 1:2) nicht mehr zur Darstellung kommen (AntigenUberschuß). In der Reihe C (50 $\mu l$ Antiserum) sind die Ringe deutlich und scharf begrenzt, aber weisen bei niedrigen Serumkonzentrationen (Verdünnung 1:8,1:16) zu kleine Durchmesser auf (Antikörperüberschuß). Optimale Vcrhältnisse ergeben sich in Reihe B (25 $\mu l$ Antiserum), indem für alle Antigenkonzentrationen scharf begrenzte Präzipitate und nicht zu kleine und nicht zu großc Durchmesser entstehen.

Wir lassen daher für die Bestimmung von saurem $\alpha_{1}$-Glykoprotein im Serum jeweils $25 \mu l$ des gewählten Antiserums in dic Agarscheiben diffundieren. 
Eine Antigenverdünnung von 1:4 dürfte optimal sein, da damit der Meßbereich weder nach oben noch nach unten eingeschränkt erscheint. Es ist auch ersichtlich, daß mit einem Verbrauch von weniger als $400 \mu l$ Antiserum in einem Arbeitsgang die Versuchsbedingungen ermittelt werden können.

Stellt man sich aber die Aufgabe, saures $\alpha_{1}$-Glykoprotein nicht im Serum, sondern in einer biologischen Flüssigkeit zu bestimmen, in der es in wesentlich geringerer Konzentration vorhanden ist (z. B. im Liquor cerebrospinalis), müssen die Versuchsbedingungen erneut ermittelt werden. Aus Abbildung 6 geht hervor, daß bei geringerem Gehalt der Agarscheibe an Immunserum trotz gleichbleibender Antigenmenge der Ringdurchmesser größer ist. Es genügt deshalb zur Untersuchung von Flüssigkeiten.mit geringem Eiweißgehalt, die Antiserummenge im Agar zu vermindern, um Ringdurchmesser im günstigen Meßbereich zu erhalten.

\section{Erstellen der Eicbkurve und Auswertung der Meßergebnisse}

Nachdem das optimale Antigen-Antikörperverhältnis gefunden ist, wird mit Hilfe einer Vergleichslösung für jeden Versuch eine Eichkurve hergestellt. Als Vergleichslösung verwenden wir in der Regel das stabilisierte Standard-Humanserum der Behringwerke mit bekanntem Gehalt der Protein-Fraktionen, gelegentlich auch Lösungen dèr Reinsubstanz. Praktisch gehen wir folgendermaßen vor: Wir beschicken die 12 Agarscheiben einer Platte mit der ermittelten optimalen Antiserummenge (s. Untersuchungstechnik, Punkt 5) und füllen die Antigen-Reservoire mit 6 verschiedenen Verdünnungen des Standard-Serums (je im Doppelversuch z. B. $1 / 1,1 / 2,1 / 4,1 / 8,1 / 16,1 / 32$ ). Die Konzentration in $\mathrm{mg} / 100 \mathrm{ml}$ wird auf der Abszisse, der Ringdurchmesser in $\mathrm{mm}$ auf der Ordinate eingetragen. Die Verbindung der Punkte bildet die Eichkurve (Abb. 5). Die gleiche Abbildung veranschaulicht auch, wie

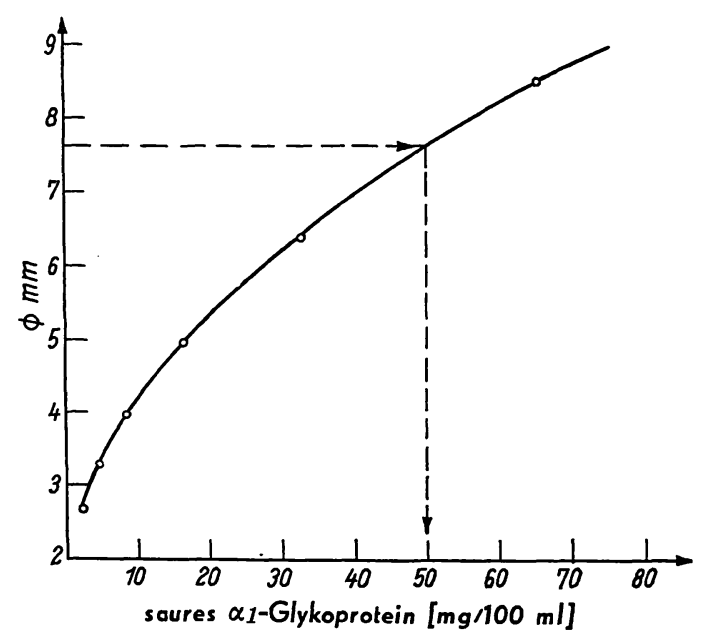

Abb. 5

Eichkurve zur Bestimmung von saurem $\alpha_{1}$-Glykoprotein Antiserum: Anti- saures $\alpha_{1}$-Glykoprotein, Behring, $20 \mu l$ pro Agarscheibe $\begin{array}{ll}\text { Antigen: } & \text { Stabilisiertes Standard-Human-Serum, Behring (unver- } \\ \text { dünnt und progressiv verdünnt bis } 1: 32 \text { ) }\end{array}$

Abszisse: Konzentration des Antigens in $\mathrm{mg} / 100 \mathrm{ml}$

Ordinate: Entsprechender Präzipitatdurchmesser in $\mathrm{mm}$.

Beispiel: Ein unbekanntes Serum wird 1:4 verdünnt angesetzt Es entsteht ein Präzipitat von 7,6 mm Durchmesser, was einem Gehalt. von $50 \mathrm{mg} / 100 \mathrm{ml}$ entspricht. Das unverdünnte Serum enthält demnach $200 \mathrm{mg} / 100 \mathrm{ml}$ saures $\alpha_{1}$-Glykoprotein

man die unbekannten Konzentrationen an saurem $\alpha_{1}$-Glykoprotein in einem zu untersuchenden Serum abliest. Bei Anwendung der gleichen Antiserummenge und einer Verdünnung des Patientenserums von 1:4 erhielt man im Doppelversuch einen Durchmesser von 7,6 mm. Dieser Durchmesser entspricht auf der Eichkurve einer Konzentration von $50 \mathrm{mg} / 100 \mathrm{ml}$. Nach Multiplikation mit dem Verdünnungsfaktor 4 erhält man als Serumkonzentration $200 \mathrm{mg} / 100 \mathrm{ml}$.

\section{Prüfung der Methode}

\section{Methodische Streunng .}

Untersuchungsmaterial: Serum-Pool aus 200 Blutspendern des Blutspendedienstes des SRK, Bern.

Antiserum: Anti- saures $\alpha_{1}$-Glykoprotein-Serum vom Kaninchen (Behring).

Am ersten Versuchstag wurden 3 Platten in der üblichen Weise vorbereitet. Pro Agarscheibe wurden $15 \mu l$ Antisaures $\alpha_{1}$-Glykoprotein gebraucht. Nach der Antikörperdiffusion pipettierten wir $4 \mu l$ des 1:4 verdünnten Serum-Pools in die frisch gestanzten Antigenreservoire. Nach 48 Stdn. erfolgte die Messung der Präzipitatringe. In gleicher Weise wurden an einem anderen Tag zwei weitere Platten vorbereitet, auf welchen noch $16 \mathrm{Be}-$ stimmungen mit dem gleichen Material durchgeführt wurden.

Insgesamt kamen 51 Bestimmungen zur Auswertung. Der mittlere Durchmesser der Präzipitatringe $\overline{\mathrm{X}}$ betrug $6,6 \mathrm{~mm}$, die Standardabweichung $\mathrm{s}= \pm 0,158 \mathrm{~mm}$, was einem Variationskoeffizienten $\mathrm{V}=2,48 \%$ entspricht.

Wenn nur die 35 Bestimmungen des ersten Tages berücksichtigt werden, erhält man ein noch exakteres Resultat, nämlich einen mittleren Präzipitatdurchmesser $\overline{\mathrm{X}}$ $=6,5 \mathrm{~mm}$, eine Standardabweichung $\mathrm{s}= \pm 0,127 \mathrm{~mm}$, einen Variationskoeffizienten $\mathrm{V}=1,9 \%$.

\section{Abbängigkeit der Ergebnisse von der Beschaffenbeit der Immunseren verschiedener Herkunft}

Untersuchungsmaterial: Serum-Pool aus 200 Blutspendern des Blutspendedienstes des SRK, Bern vom 18. 1. 1968. Antisera: Anti-IgG-Immunserum, lyophilisiert, Sevac, Prag. Anti-IgG-Immunserum Behringwerke.

Referenzserum: Standard-Human-Serum Behring

An zwei verschiedenen Tagen wurde mit Hilfe von zwei verschiedenen Immunseren das $\mathrm{IgG}$ in einem Normalserum (Pool aus 200 Spendern) bestimmt. Von beiden Immunseren verwendeten wir die glciche Menge (40 $\mu l$ pro Agarscheibe), erstellten je eine Eichkurve und erhielten am ersten Tag $928 \mathrm{mg} / 100 \mathrm{~m} / \mathrm{IgG}$ mit beiden Immunseren. Am zweiten Tag betrugen die Werte beider Bestimmungen $936 \mathrm{mg} / 100 \mathrm{ml}$.

Die Ergebnisse des gleichen Tages wichen also voneinander überhaupt nicht ab, die an verschiedenen Tagen gemessenen Werte ergaben einen Unterschied von nicht ganz $1 \%$.

Im ganzen wurden für diesen Versuch 40 Einzelbestimmungen verwertet (4 Doppelbestimmungen für die Eichkurve, je 1 Doppelbestimmung für die Normalseren).

\section{Abbängigkeit des Präzipitatdurcbmessers voin der Anti- körper-Konzentration}

Wie bereits erwähnt, nimmt mit zunehmender Antikörperkonzentration bei gleicher Antigenmenge der Durchmesser der Präzipitate ab. Diese Tatsache nützen wir bei der hier beschriebenen Methode aus, wenn zu große Präzipitatringe entstehen, indem wir in solchen Fällen mehr Immunserum pro Agarscheibe verwenden. 


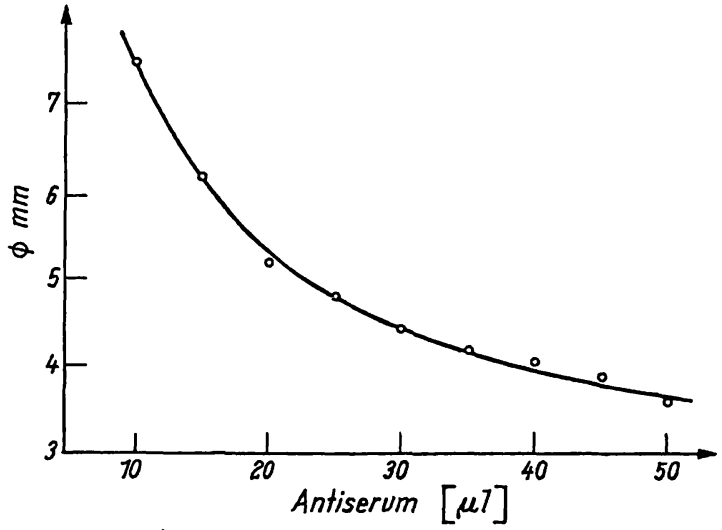

Abb. 6

Abhängigkeit des Präzipitatdurchmessers von der Antiserummenge

Antiserum: Anti- saures $\alpha_{1}-$ Glykoprotein, Behring
Antigen: dünnt.

Je zwei Agarscheiben wurden mit 10, 15, 20 usw. bis $50 \mu l$ Antiserum beschickt. 48 Stdn. später wurden $4 \mu l$ Serum in die Antigenreservoire eingefüllt. Die Messung erfolgte nach 36 Stdn. Mit zunehmender Ant körperkonzentration nimmt der Präzipitatdurchmesser $a b$

Abbildung 6 veranschaulicht diese Versuchsanordnung: Je 2 Agarscheiben wurden mit 10,1.5, 20 und so fort bis $50 \mu l$ Anti- saures $\alpha_{1}$-Glykoprotein Behring beschickt. Nach Diffusion des Antikörpers wurden $4 \mu l$ 1:2 verdünntes Standard-Human-Serum Behring in jedes Antigenreservoir eingefüllt. Die Messung der Präzipitate erfolgte nach 36 Stdn. Die Ergebnisse wurden auf ein Koordinatensystem eingetragen, dessen Ordinate die Präzipitatdurchmesser in mm, dessen Abszisse die Antikörper-Menge pro Agarscheibe angibt. Im Bereich niedriger Antikörper-Konzentration ist der Kurvenverlauf praktisch linear (auf der Abbildung von 10 bis $20 \mu l$ Immunserum pro Agarscheibe), bei weiterer $\mathrm{Zu}$ nahme der Antikörper-Konzentration wird die $\mathrm{Ab}$ nahme des Präzipitatdurchmessers immer geringer. $\mathrm{Da}$ mehr als $50 \mu l$ Immunserum vom Agar nicht mehr vollständig aufgenommen werden, sind höhere AntikörperKonzentrationen nicht anwendbar. Mit weniger als $10 \mu l$ Anti-saures $\alpha_{1}$-Glykoprotein-Serum bilden sich nur sehr flaue Präzipitate, die nicht mehr gemessen werden können. Aus dem Versuch geht die früher erwähnte Tatsache hervor, daß durch einen von Fall zu Fall optimal gewählten Antikörpergehalt der Agarscheibe bei verschiedensten Antigenmengen Präzipitatringe mit .günstigem Durchmesser erreicht werden können.

Eine weitere Anwendungsmöglichkeit dieses Prinzips, die wir allerdings in unserer Arbeit nicht weiter verfolgt haben, besteht im folgenden: es kann die ganze Fragestellung umgekehrt werden, indem man mit Hilfe einer bekannten Antigenlösung und eines bekannten Antiserums den Antikörper-Gehalt eines unbekannten Immunserums ermittelt.

\section{Empfindlichkeit}

Bis zu einem gewissen Grad läßt sich die Empfindlichkeit der Methode erhöhen, indem der Antikörpergehalt des Agars herabgesetzt wird, wobei die Grenze durch die Sichtbarkeit der Präzipitate gesetzt ist. Wir konnten in geeigneter Versuchsanordnung noch $0,002 \mathrm{mg} / \mathrm{m} l$ bzw. (in $4 \mu l$ entsprechend unserem Ansatz) $0,008 \mu \mathrm{g}$ Reinsubstanz nachweisen, wie aus folgendem Versuch hervorgeht.

Aus einer Reinlösung saures $\alpha_{1}$-Glykoprotein mit einem Gehalt von $2 \mathrm{mg} / \mathrm{ml}$ (Behring) wird eine Verdünnungsreihe $(1: 2,1: 4,1: 8$ usw.) hergestellt und mit drei Antikörper-Konzentrationen (Anti- saures $\alpha_{1}$-Glykoprotein Behring), nämlich 5, 10, $20 \mu \mathrm{l}$ pro Agarscheibe angesetzt. Bei der stärksten Antikörper-Konzentration erhalten wir meßbare Präzipitate bis zu einer Verdünnung von 1:64, was ungefähr $0,03 \mathrm{mg} / \mathrm{m} l$ saures $\alpha_{1}$-Glykoprotein entspricht. Im Versuch mit $10 \mu l$ Antiserum pro Agarscheibe können wir noch wesentlich geringere Mengen bestimmen, erhalten wir doch bis zu einer Verdünnung von $1: 512$ (=etwa $0,004 \mathrm{mg} / \mathrm{m}$ ) ablesbare Resultate, bei einer Verdünnung von 1:1024 entsteht immer noch ein schmales, noch eben sichtbares aber nicht mehr meßbares Präzipitat unmittelbar um das Antigenreservoir. Setzen wir den Antikörpergehalt noch weiter herab (5 $\mu$ l Immunserum pro Agarscheibe) entstehen nur sehr flaue Präzipitate, die nicht mehr gemessen werden können.

\section{Diskussion}

Die von Mancini und Mitarbeitern (1) ausgearbeitete Radial-Diffusionsmethode ermöglicht die quantitative Bestimmung einzelner Plasmaproteine auch im klinischen Laboratorium. Sie bedeutet eine wichtige Ergänzung zur Immunoelektrophorese (4), die in erster Linie eine qualitative Beurteilung und höchstens eine grobe quantitative Schätzung erlaubt.

Bis dahin standen aber einer routinemäßigen Anwendung der Mancini-Methode einige Schwierigkeiten im Weg. Einerseits ist die Herstellung der Platten im eigenen Labor kompliziert und heikel und beansprucht verhältnismäßig große Mengen Antiserum; andererseits sind die im Handel erhältlichen Immunoplatten teuer, und sie werden nur mit einer einzigen Antikörper-Konzentration geliefert, so daß die Anwendungsmöglichkeiten begrenzt sind. Dies veranlaßte uns, die Mancini-Methode zu modifizieren, in der Absicht, die erwähnten Schwierigkeiten zu umgehen.

Ein erster Unterschied der von uns entwickelten $\mathrm{Me}-$ thode gegenüber der Mancini-Methode liegt in der Verkleinerung der Dimensionen des Agargels, die so gewählt sind, daß darin nur noch eine Einzelbestimmung vorgenommen wird. Dadurch läßt sich Antiserum sparen. Für unsere Zwecke bewährten sich Agarscheiben von $12 \mathrm{~mm}$ Durchmesser und $2 \mathrm{~mm}$ Dicke. Zur exakten Herstellung dieser Gelscheiben haben sich die unter Instrumentarium beschriebenen Plexiglasplatten bewährt.

Die gewünschte Menge des monospezifischen Immunserums wird auf den erkalteten Agar pipettiert und diffundiert in $48 \mathrm{Stdn}$. gleichmäßig in den Agar hinein. Dadurch wird das Erhitzen des Immunserums vermiedẹn. Es werden nur die für den vorgesehenen Versuch benötigten Agarscheiben mit Immunserum ver- 
setzt, wodurch Immunserum gespart wird. Einwandfreie Antigenreservoire in der Mitte der Scheiben erhalten wir mit Hilfe einer eigens entworfenen Stanzschablone (s. Instrumentarium).

Durch die Verkleinerung der Dimensionen und die Vereinfachung der Zubereitung des Immungels kann die Methode in jedem klinischen Laboratorium angewendet werden. Die einzelnen Scheiben sind voneinander unabhängig; man kann zum Beispiel auf einer Platte bis zu 12 verschiedene Substanzen bestimmen oder, indem man den Antikörpergehalt von Scheibe zu Scheibe anders wählt, mit getingstem Verbrauch an Immunserum das optimale Antigen/Antikörperverhältnis für einen Versuch ermitteln.

Die Prüfung der Methode durch mehrmalige Untersuchung der gleichen Eiweißlösung ergab eine sehr gute Reproduzierbarkeit der Ergebnisse mit geringer methodischer Streuung. Die Empfindlichkeit ist ebenso hoch wie diejenige der Originalmethode nach MANCINI.
Dank der großen Anpassungsfähigkeit und der hohen Empfindlichkeit der Methode ergeben sich Anwendungsmöglichkeiten auch in Gerichtsmedizin, Bakteriologie und Virologie, sowie beil der Untersuchung von Urin, Liquor usw.

Die von uns bei der Untersuchung von Blutspendern gefundenen Normalwerte von Plasmaproteinen stimmen weitgehend mit den Literaturangaben überein (8).

Diese Arbeit wurde mit der Unterstützung des Schweizerischen Nationalfonds zur Förderung der wissenschaftlichen Forschung durchgeführt.

Die SEVAC Prag und die Behringwerke Marburg/Lahn haben uns freundlicherweise einen Teil der Immunseren und Reinsubstanzen zur Verfügung gestellt. Vom Blutspendedienst des SRK haben wir die Normalseren erhalten. Wir danken den Verantwortlichen dieser Unternehmen bestens. Herr Dr. Rosserrr, Aarau und Herr MEYER vom Physiologischen Institut der Universität Bern waren uns bei der Wahl des Materials für die Platten und bei deren Herstellung behilflich. Ihnen sei hiermit bestens gedankt. Wir danken auch Fräulein E. KumMare, Fräulein C. REICH, Fräulein N. RENAUd und Fräulein E. SchLUMPF für ihre Mitarbeit.

\section{Literatur}

1. Mancini, G., J.P. Vaerman, A. O. Carbonara und J.F. Heremans, Immunochemistry 2, 235 (1965). - 2. Petrie, G. F., Brit. J. exp. Path. 13, 380 (1932). - 3. FeInBERG, J. G., Internat. Arch. Allergy 11, 129 (1957). - 4. Grabar, P. und C. A. WiL- urams, Biochim. biophysica Acta, Amsterdam 10, 193 (1953). 5. OuchrerLonY, O., Thesis, Stockholm (1949). - 6. Oudin, J., Meth. med. Res. 5, 235 (1952). - 7. Afonso, E., Clin. chim. Acta 13, 107 (1966). - 8. GoldER, S. und H. KELLER, in Vorbereitung.

Dr. H. Keller CH-3004 Bern Tiefenauspital 